\title{
Hemolytic Anemia: A Rare Side Effect Related with IVIG Therapy in Stevens-Johnson Syndrome
}

\author{
(1) Cüneyt Kara', (1) Sevim Baysak², (1) Zuhal Erçin², (1) Tuğba Falay Gür², (1) Sevil Savaș Erdoğan², (1) Bilal Doğan²
}

1Batman Regional State Hospital, Clinic of Dermatology, Batman, Turkey

2Istanbul Sultan 2. Abdulhamid Han Training and Research Hospital, Clinic of Dermatology, Istanbul, Turkey

\section{ABSTRACT}

Intravenous immunoglobulin (IVIG) is commonly used as replacement therapy in immunodeficiency disorders and in higher doses for certain autoimmune and inflammatory conditions. Dermatomyositis, Kawasaki disease, pyoderma gangrenosum, Stevens-Johnson syndrome (SJS), toxic epidermal necrolysis, pemphigus group and bullous pemhigoid are the most common indications for IVIG treatment. Common side effects of IVIG include headache, flu-like symptoms, nausea, chills, rash, backache, and hypotension. Rare serious adverse events, including anaphylaxis, acute renal failure, aseptic meningitis, transfusion-related acute lung injury, and thrombo-embolic events may also ocur. Only a few cases of hemolytic anemia associated with IVIG therapy have been reported to date. We present a case of hemolytic anemia after IVIG therapy in a patient with SJS.

Keywords: Stevens-Johnson syndrome, Intravenous immunoglobulin, Hemolytic anemia

\section{Introduction}

Stevens-Johnson syndrome (SJS) and toxic epidermal necrolysis (TEN) are rare and serious cutaneous adverse reactions, associated with high mortality [1]. SJS/TEN can be defined as fissuration of the necrotic epidermis and erosion of mucous membranes of varying severity [2]. SJS/TEN are usually caused by an allergic reaction based on drugs including antibiotics, non-steroidal anti-inflammatory agents, anticonvulsants and allopurinol [3,4]. Infections, including mycoplasma infection, are also known as possible causes of SJS in yong patients $[4,5,6]$. Many therapeutic methods are used in its treatmet including systemic steroids, plasmapheresis and immunosuppressant drugs $[4,7,8]$. Its thought that fas blocking antibodies occuring naturally duration of intravenous immunoglobulin (IVIG) inhibit fas mediated keratinocyte apoptosis [9] and therefore they are used in treatment [10]. We present a case with SJS developed hemolytic anemia during IVIG treatment.

\section{Case Report}

A 35-year-old man was admitted to our hospital with flu-like symptoms and a widespread rash that was worsening during one week period. One day before the rash the patient had taken dexketoprofen for his backache. Additionally he had been taking lamotrigine, trifluoperazine and buspirone for four months for somatoform disorder which are prescribed by his psychiatrist. His family history was unremarkable. The patient was a non-smoker and had denied alcohol and illicit drug use.

On general examination the patient had malaise and low-grade fever. Dermatological examination showed target lesions and erythematous plaques on his trunk, upper and lower extremities. Some plaques had pustule formation in the center of the lesions (Figures 1, 2). In addition, Nikolsky's sign was positive both on the lesional and healthy skin. Histopathological examination of the lesional skin revealed keratinocyte apoptosis/necrosis 
and dermoepidermal junction detachment. All of the infectious etiologies have been ruled out with negative blood cultures and appropriate tests. According to the clinical findings and biopsy results, we diagnosed the patient as SJS.

As soon as we diagnosed the patient as SJS, we cessated all of his drugs upon permission of psychiatry department. We started combination therapy with systemic corticosteroid and IVIG. The patient was $70 \mathrm{~kg}$ and was treated with four consecutive doses of

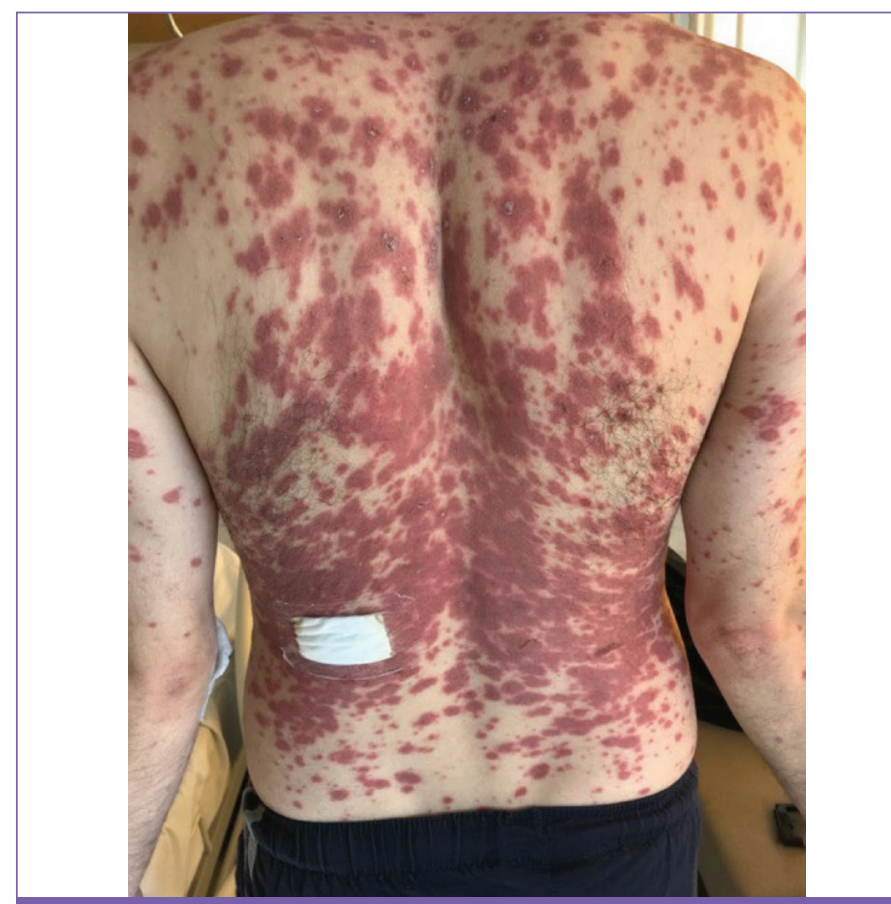

Figure 1. Erythematous papules plaques and detachment on his trunk and upper extremity

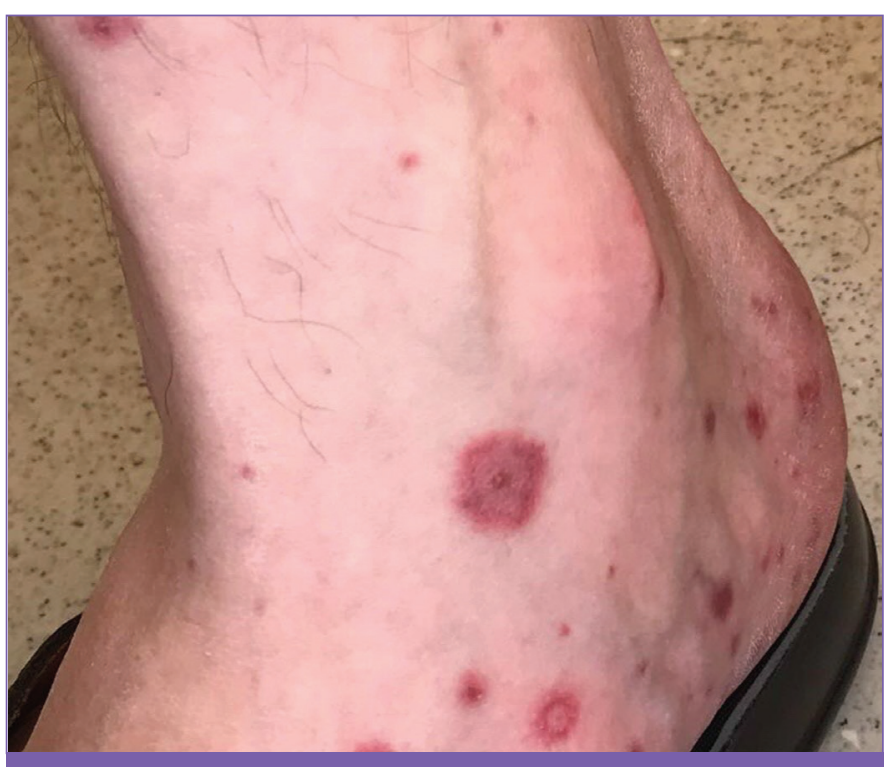

Figure 2. Atypical target lesion on his foot
IVIG $0.75 \mathrm{~g} / \mathrm{kg} /$ day and methylprednisolone $60 \mathrm{mg} /$ day for four days. After four days, erytematous plaques have resolved and Nikolsky's sign had become negative. The patient's temperature also returned to normal. Upon this, we stopped the combination treatment and followed the patient without any intervention. Before starting therapy, the patient's hemoglobin level was 14.93 $\mathrm{g} / \mathrm{dL}$ and total bilirubin level was $1.1 \mathrm{mg} / \mathrm{dL}$ (indirect bilirubin 0.8 $\mathrm{mg} / \mathrm{dL})$. The hemoglobin level started to decrease $(12.52 \mathrm{~g} / \mathrm{dL})$ after the first dose of IVIG therapy. During the following days, on which the patient was taking combination therapy of IVIG and systemic corticosteroid, we observed almost similar hemoglobin levels such as $12.62 \mathrm{~g} / \mathrm{dL}, 12.00 \mathrm{~g} / \mathrm{dL}$ and $12.40 \mathrm{~g} / \mathrm{dL}$. But on hospital day 11, which was six days after ending the combination treatment upon clinical cure of SJS, we observed that the patient had scleral icterus. Laboratory results showed decreased hemoglobin level of $10.7 \mathrm{~g} / \mathrm{dL}$ and increased total bilirubin level of $1.9 \mathrm{mg} / \mathrm{dL}$ (indirect bilirubin level $1.28 \mathrm{mg} / \mathrm{dL}$ ). We consulted the patient to the hematology department by which some additional laboratory investigation has been undertaken. Haptoglobin level was found $<8 \mathrm{mg} / \mathrm{dL}$, direct Coombs test was positive, reticulocyte count was elevated $6 \%$ and the other laboratory values including lactate dehydrogenase (LDH), total iron binding capacity, platelet count, vitamin B12, folic acid, prothrombin time, partial thromboplastin time and international normalized ratio were in the normal range. Besides scleral icterus the patient didn't show any other clinical finding. Hematology department diagnosed the patient as hemolytic anemia and recommended observing the patient in the hospital without any intervention. At follow up, five days later, on hospital day 16, we noticed that laboratory values were returning to normal such as hemoglobin level being $11.2 \mathrm{~g} / \mathrm{dL}$, total bilirubin level $1.1 \mathrm{mg} /$ $\mathrm{dL}$ (indirect bilirubin $0.85 \mathrm{mg} / \mathrm{dL}$ ), haptoglobin level $18 \mathrm{mg} / \mathrm{dL}$ and direct Coombs test has become negative. Hemoglobin levels started to increase dramatically and reached $13.2 \mathrm{~g} / \mathrm{dL}$ and $14.6 \mathrm{~g} /$ $\mathrm{dL}$, two and three weeks after the diagnosis of hemolytic anemia, respectively.

\section{Discussion}

SJS is a rarely encountered disease but has a high mortality. After the diagnosis of SJS or TEN, the culprit drug must be cessated immediately. Supportive care and specific medical treatment is also essential. Systemic corticosteroid, IVIG and cyclosporine are some of the mostly recommended pharmacological agents for the medical treatment. IVIG contains natural anti-Fas antibodies and other immunomodulators that may prevent apoptosis [11]. In our case we applied combined IVIG and systemic corticosteroid treatment.

Rare serious adverse events, including anaphylaxis, acute renal failure, aseptic meningitis, transfusion-related acute lung injury, and thrombo-embolic events may ocur during IVIG therapy [12]. 
Hemolysis is a rare side effect of IVIG therapy and only a few cases of hemolytic anemia associated with IVIG therapy have been reported to date $[13,14]$. In a case series of 16 patients; some severe cases required blood transfusion whereas most of the mild cases recovered spontaneously without any intervention [15]. Although not clear, the underlying mechanism of hemolytic anemia is thought to be related to autoimmunity.

We established the diagnosis according to the proposed criteria for the standardized case definition of hemolysis associated with the use of IVIG as developed by the Canadian IVIG Hemolysis Pharmacovigilance Group. These criteria include the onset of hemolysis within 10 days of IVIG administration with a decrease in hemoglobin of greater than or equal to $10 \mathrm{~g} / \mathrm{L}(1.0 \mathrm{~g} / \mathrm{dL})$; a positive direct antiglobulin test (DAT) result; and at least 2 of the following: increased reticulocyte count; increased LDH level; low haptoglobin level; unconjugated hyperbilirubinemia; hemoglobinuria; and the presence of significant spherocytosis in the absence of history or examination findings of an alternate cause of blood loss or a negative DAT result [16]. Our patient's hemoglobin level was normal at the time of admission to our hospital $(14.93 \mathrm{~g} / \mathrm{dL})$. After first dose of IVIG therapy, the hemoglobin level started to decrease gradually until $10.7 \mathrm{~g} / \mathrm{dL}$ with the clinical finding of scleral icterus and laboratory findings of decrease in hemoglobin level greater than $1 \mathrm{~g} / \mathrm{dL}$ (4.23 g/dL); positive direct Coombs test, unconjugated hyperbilirubinemia and low haptoglobin level.

Before establishing this diagnosis, it is suggested to exclude other hematological disorders including immune thrombocytopenia, heparin-induced thrombocytopenia, disseminated intravascular coagulation and iron deficiency anemia.

Identified risk factors for IVIG related hemolytic anemia include female gender, non-O blood type and administration of IVIG with high titers of anti-A/B IgG antibodies. The patient had AB blood type and had received $3 \mathrm{~g} / \mathrm{kg}$ IVIG totally and these factors might have contributed to the development of hemolysis after IVIG therapy in our case [17].

In summary, we have described a patient with acute hemolysis after infusion of IVIG $0.75 \mathrm{~g} / \mathrm{kg} /$ day for SJS. Hemolytic anemia in our case was mild and has improved without any intervention. Combined systemic corticosteroid therapy may have weakened the hemolytic reaction. IVIG treatment is used for a wide variety of indications in dermatology. Therefore, dermatologists should be cautious about hemolytic anemia after IVIG therapy particularly in the early follow up period.

\section{Ethics}

Informed Consent: Consent form was filled out by all participants.

Peer-review: Internally peer-reviewed.

\section{Authorship Contributions}

Surgical and Medical Practices: C.K., S.B., B.D., Concept: C.K., S.B., Z.E., Design: C.K., S.B., T.F.G., S.S.E., B.D., Data Collection or Processing: C.K., S.B., Analysis or Interpretation: C.K., S.B., Z.E., T.F.G., S.S.E., B.D., Literature Search: C.K., S.B., Z.E., T.F.G., Writing: C.K., S.B.

Conflict of Interest: No conflict of interest was declared by the authors.

Financial Disclosure: The authors declared that this study received no financial support.

\section{References}

1. Paulmann M, Mockenhaupt M. Severe drug-induced skin reactions: clinical features, diagnosis, etiology, and therapy. J Dtsch Dermatol Ges 2015;13:625645.

2. Bastuji-Garin S, Rzany B, Stern RS, Shear NH, Naldi L, Roujeau JC. Clinical classification of cases of toxic epidermal necrolysis, Stevens-Johnson syndrome, and erythema multiforme. Arch Dermatol 1993;129:92-96.

3. Roujeau JC, Stern RS. Severe adverse cutaneous reactions to drugs. N Engl J Med 1994;331:1272-1285.

4. Yamane Y, Aihara M, Ikezawa Z. Analysis of Stevens-Johnson syndrome and toxic epidermal necrolysis in Japan from 2000 to 2006. Allergol Int 2007; 56:419-425.

5. Wetter DA, Camilleri MJ. Clinical, etiologic, and histopathologic features of Stevens-Johnson syndrome during an 8-year period at Mayo Clinic. Mayo Clin Proc 2010;85:131-138.

6. Kunimi Y, Hirata Y, Aihara M, Yamane Y, Ikezawa Z. Statistical analysis of Stevens-Johnson syndrome caused by Mycoplasma pneumonia infection in Japan. Allergol Int 2011;60:525-532.

7. Kirchhof MG, Miliszewski MA, Sikora S, Papp A, Dutz JP. Retrospective review of Stevens-Johnson syndrome/toxic epidermal necrolysis treatment comparing intravenous immunoglobulin with cyclosporine. J Am Acad Dermatol 2014;71:941-947.

8. Egan CA, Grant WJ, Morris SE, Saffle JR, Zone JJ. Plasmapheresis as an adjunct treatment in toxic epidermal necrolysis. J Am Acad Dermatol 1999;40:458-461.

9. Viard I, Wehrli P, Bullani R, Schneider P, Holler N, Salomon D, Hunziker T, Saurat JH, Tschopp J, French LE. Inhibition of toxic epidermal necrolysis by blockade of CD95 with human intravenous immunoglobulin. Science 1998;282:490-493.

10. Feldmeyer L, Kerdel FA, French LE. Use of intravenous immunoglobulin in toxic epidermal necrolysis. Arch Dermatol 2011;147:1440-1441.

11. Khalili B, Bahna SL. Pathogenesis and recent therapeutic trends in StevensJohnson syndrome and toxic epidermal necrolysis. Ann Allergy Asthma Immunol 2006;97:272-280.

12. Orange JS, Hossny EM, Weiler CR, Ballow M, Berger M, Bonilla FA, Buckley R, Chinen J, El-Gamal Y, Mazer BD, Nelson RP Jr, Patel DD, Secord E, Sorensen RU, Wasserman RL, Cunningham-Rundles C; Primary Immunodeficiency Committee of the American Academy of Allergy, Asthma and Immunology. Use of intravenous immunoglobulin in human disease: a review of evidence by members of the Primary Immunodeficiency Committee of the American Academy of Allergy, Asthma and Immunology. J Allergy Clin Immunol 2006;117(4 Suppl):525-553.

13. Morgan S, Sorensen P, Vercellotti G, Zantek ND. Haemolysis after treatment with intravenous immunoglobulin due to anti-A. Transfus Med 2011;21:267270 . 
14. Dalakas MC. Mechanism of action of intravenous immunoglobulin and therapeutic considerations in the treatment of autoimmune neurologic diseases. Neurology 1998;51(6 Suppl 5):2-8.

15. Daw Z, Padmore R, Neurath D, Cober N, Tokessy M, Desjardins D, Olberg B, Tinmouth A, Giulivi A. Hemolytic transfusion reactions after administration of intravenous immune (gamma) globulin: a case series analysis. Transfusion 2008;48:1598-1601.
16. Taylor E. Intravenous immune globulin (IVIG): hemolytic reactions. Can Adverse React Newsl 2013;19:1-3.

17. Ririe MR, Blaylock RC, Morris SE, Jung JY. Intravenous immune globulin therapy for Stevens-Johnson syndrome/toxic epidermal necrolysis complicated by hemolysis leading to pigment nephropathy and hemodialysis. J Am Acad Dermatol 2013;69:221-225. 